\title{
Dental Emergency Attendance at an Australia Tertiary Children's Hospital
}

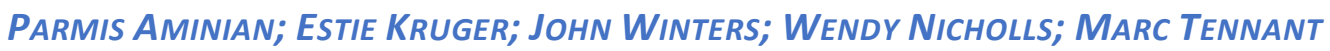

The University of Western Australia

35 Stirling HWY, Crawley Perth Western Australia 6009, Australia

Correspondence: parmis.aminian@uwa.edu.au

\begin{abstract}
Objective: Objective: Dental emergencies are a significant impact on the health system. The resource needs are complex and consume services in the tertiary health sector. It is important that we examine the reasons and types of attendances to look for ways to mitigate this demand. The aim was to identify the rate of dental emergencies according to age groups, genders and Indigenous status.
\end{abstract}

Method: A retrospective analysis of dental emergencies at the Princess Margaret Hospital (PMH; tertiary children hospital in Perth) was performed.

Setting: The study included data from hardcopy files of patients admitted to the PMH.

Main outcome measures: Main outcome measures: The records of 239 children who attended the $\mathrm{PMH}$ in Perth with dental emergency problems during the first 3 months of 2017 were analyzed.

\section{INTRODUCTION}

In the developed world, the dental health of children has substantially improved, over the last 50 years. [1] Today, in Australia (and most states including Western Australia), for example, the average number of decayed or treated teeth in 6-years old is near one, and prevalence of any dental caries has been
Findings: The major reasons for dental emergencies were infection and trauma. The most common age group was children between 3 to 6 years old. In this age group, boys attended more than girls due to dental injury. Although there were equal presentations of dental infection and dental trauma cases, dental infection cases mostly required hospitalization and treatment under general anesthetic.

Conclusion: While some dental emergencies are unavoidable, increasing awareness about dental hygiene, regular checkups and early dental treatments in children could decrease emergency visits and prevent conditions such as dental infections.

Keywords: dental emergency, children, Western Australia

reported as less than $40 \%$. [2] Notwithstanding this massive improvement in oral health, there continues to be a small and intractable number of children that suffer dental disease. In Western Australia, even with a universal coverage School Dental Service (free of cost), hospital admissions for dental conditions continue to be a substantial burden on society. [2] Previous research has found dental 
conditions to be the 5th and 6th most common cause of a hospital admission for a primary and secondary school-aged child in Western Australia (WA) respectively. [3] Against this dichotomy of substantially good oral health overall is an ongoing small, but significant level of hospital episodes caused by dental caries. It is important that an understanding be gained of the case histories of patients attending for in-patient emergency dental care. In Western Australia, there is a single primary site for emergency dental care involving the use of general anesthesia; the jurisdictions only children's hospital, Princess Margaret Hospital (PMH) in Perth (the capital of the State of Western Australia). The vast majority of caseload (estimated at over $85 \%$ ) is accepted for care through this facility. The aim of this study was to analyse the demographic profile, primary reasons for attendance, and if treated as an in- or outpatient for cases attending for emergency dental care at $\mathrm{PMH}$.

\section{METHODS}

Ethics:

This study was a retrospective record analysis of children with dental complaints who visited the $\mathrm{PMH}$ emergency department during the first 3 months of 2017.

The data were obtained from hard-copy files of patients after creating the GEKO audit Quality Activity (number: 14390).

The following information was collected: age, gender, Indigenous status, presentation in ED, date of dental treatment, the primary reason for presentation (facial Injury, dental infection, etc.), In-patient or Out-patient treatment, and whether a patient independently attended ED or by a referral from elsewhere. This study was not designed to examine the specific diagnostic cause or precise treatment plans but focused on the principal reason for attendance and primary treatment pathway.
Statistics were then derived from the data set. Standard quantitative analyses were conducted by using Excel formulas (Microsoft Redmond USA). IBM SPSS version 23 (IBM, New York, NY, USA) were used to determine significance of differences in proportions of independent samples by using Pearson's chisquare tests. As the number of cases in some of the subgroups were very small, statistical analysis were limited.

\section{RESULTS}

This study reviewed a random sample of records ( $n=23940 \%$ ) from the first quarter of 2017.

\section{Patient demographics}

Of 239 patients, there were 128 boys (53.6\%) and 111 girls (46.4\%). Of the $239,12 \%$ were of Aboriginal and Torres Strait Islander descent (Indigenous people of Australia) and 3\% were refugees (Table 1 ).

\begin{tabular}{|l|c|c|c|c|}
\hline & Refugee(\%) & ATSI(\%) & Other(\%) & Total(\%) \\
\hline Female & $2(1.8)$ & $13(11.7)$ & $96(86.5)$ & $111(100.0)$ \\
\hline Male & $5(3.9)$ & $15(11.7)$ & $108(84.4)$ & $128(100.0)$ \\
\hline Total & $7(2.9)$ & $28(11.7)$ & $204(85.4)$ & $239(100.0)$ \\
\hline
\end{tabular}

Table 1. The number and percent of patients of different demographic groups attending for care.

Ages ranged up to 16 years old (the limit of entry for this hospital), with an average of 5.9 years. Peak attendance for females and males was 5 years old, with three quarters of attendance for those under 7 years and 8 years for females and males respectively (Table 2 ).

The reason for attendance differed with age, whilst overall attendance was about a third infants, a quarter preschoolers, and a third primary, and the remaining being secondary school students (Table 3). The reasons for attendance for infants included infective causes (a quarter), whilst for preschoolers this 
was over three quarters (with females being over $80 \%$ ). For primary school ages about $60 \%$ of females attended for infective causes, while only $44 \%$ of males attended for the same reason (Table 3).

Among Indigenous patients, $57.1 \%$ attended due to infective conditions and $42.9 \%$ because of injury. In the Non-Indigenous group $47.9 \%$ attended due to infective conditions, and $52.2 \%$ due to other conditions (Table 4). The differences in proportions between Indigenous and non-Indigenous patients attending for injury and infections were not statistically significant in both instances $(P<0.05$, Pearson chi-square). It indicated that the predominant reason for attendance in the dental emergency department among Indigenous children was for dental infections, while the most frequent reason for non-Indigenous children was Injury. The only reason for attendance among the refugee patients was for dental infection, but the total number was low.

\section{Presentation and admission}

The majority of patients ( $n=136,57 \%$ ) presented directly to the hospital. More than half of children ( $n=157,66 \%)$ were admitted and treated as an in-patient, while the remainder ( $n=82,34 \%$ ) was treated as outpatients. The majority of patients who attended due to dental infection were treated under general anesthesia as in-patients ( $n=103 / 117,88 \%)$. On the other hand, less than half of patients ( $n=54 / 117,46 \%$ ) who attended for trauma (or other dental conditions such as frenulum entrapment, viral stomatitis, eruption haematoma) needed to be treated under general anesthesia (Table 5).

\section{Reason for Presentation}

The main reasons for patients to present were dental infection and trauma. From the total 239 patients, $49 \%$ had tooth infections or abscesses, $49 \%$ had experienced trauma, with the remaining attending for other dental problems (Table 5). There was a difference in reasons for attendance at different ages (Figure 1). For ages below 3 years, trauma was the primary reason for attendance, whilst from 3 years through to 9 years, infective issues were the primary reason, and then for those above age 9 trauma returned to the fore (Figure 1).

\section{DISCUSSION}

This retrospective study assessed the demographic of children attending for in dental emergencies at PMH.

The results revealed that dental infection and trauma were the major causes of dental emergency visits (98\% all together). Furthermore, two thirds of patients (65.6\%) who were treated as in-patients had dental infection (Table 5). In summary, the most common cause for dental hospitalisation was dental caries or abscesses. Previous studies have reported that dental caries are the most common reason of oro-dental related hospitalisation in children. $[3,4,5,6]$ The children who needed general anesthesia for treatment were treated for infection related problems. Tertiary care from dental sources is a result of conditions that can be intercepted and treated as out-patients or in the community.

According to a previous study in Western Australia, about $95 \%$ of the dental hospitalisation cost was spent on nonIndigenous children. [7] In the present study, the numbers of non-Indigenous children who attended were more than that of Indigenous children. However, when adjusting for total population, Indigenous children appeared over-represented in infective causes. Particularly considering that most Indigenous people live outside of major city areas, and only a third (34.8\%) of all Indigenous people lived in major city areas. In contrast, almost 
three quarters $(71.3 \%)$ of non-Indigenous people lived in major city areas. [8] Moreover, Indigenous people often use Indigenous community health services. $[9,10]$ As a result, providing dental emergency services in Indigenous community centers may be a valuable strategy to prevent dental disease as well as decrease the frequency of emergency attendance at the tertiary hospitals.

A previous study has reported that males experienced dental injuries more often than females. [11] The present study found similar results, with the male to female ratio being $1.25: 1$. It also found that the most common age group attending the emergency department because of dental injury was those under the age of 3 years old. Young children needing emergency treatment may pose a challenging treatment situation for both patient and dentist in the community setting, and thus was not an unexpected finding.

\section{CONCLUSION}

It is important to focus on preventive dental care for children in order to decrease dental infections that require emergency treatment. It can result in beneficial outcomes, such as a reduction in the load of emergency services, emergency staff pressure, waiting times in emergency departments, and also lower government costs providing these services. Therefore, strategies proposed should include dental preventive services, and efforts to improve the awareness of parents regarding the importance of dental hygiene in children, and early treatment of dental disease before emergency treatment becomes necessary. Dental hygienists employed in community centers, childcare centres and schools can implement preventive and effective programs to achieve this purpose. More research is needed to identify the most effective and appropriate strategies enable to achieve these goals.

Table 2. The age (years) distribution of patients attending for care

\begin{tabular}{|c|c|c|c|c|c|c|c|c|c|}
\hline & \multicolumn{4}{|c|}{ Female } & \multicolumn{4}{|c|}{ Male } & \multirow{2}{*}{$\begin{array}{c}\text { All } \\
\text { Grand } \\
\text { Total }\end{array}$} \\
\hline Age & Refugee & ATSI & Other & Total(\%) & Refugee & ATSI & Other & Total(\%) & \\
\hline 1 & & 1 & 12 & $13(11.7)$ & & 1 & & $1(0.7)$ & 14 \\
\hline 2 & & & 9 & $9(8.1)$ & & & 12 & $12(9.3)$ & 21 \\
\hline 3 & & 1 & 10 & $11(9.9)$ & & 2 & 16 & $18(14)$ & 29 \\
\hline 4 & & 1 & 13 & $14(12.6)$ & & 3 & 13 & $16(12.5)$ & 30 \\
\hline 5 & 1 & 3 & 16 & $20(18)$ & 1 & 2 & 16 & $19(14.8)$ & 39 \\
\hline 6 & & 3 & 8 & $11(9.9)$ & 1 & & 10 & $11(8.5)$ & 22 \\
\hline 7 & & 1 & 5 & $6(5.4)$ & 1 & 1 & 9 & $11(8.5)$ & 17 \\
\hline 8 & & 1 & 7 & $8(7.2)$ & 1 & 3 & 4 & $8(6.2)$ & 16 \\
\hline 9 & & 1 & 8 & $9(8.1)$ & & & 6 & $6(4.6)$ & 15 \\
\hline 10 & 1 & 1 & & $2(1.8)$ & & 1 & 4 & $5(3.9)$ & 7 \\
\hline 11 & & & 3 & $3(2.7)$ & & & 6 & $6(4.6)$ & 9 \\
\hline 12 & & & 2 & $2(1.8)$ & & & 6 & $6(4.6)$ & 8 \\
\hline 13 & & & 1 & $1(0.9)$ & 1 & & & $1(0.7)$ & 2 \\
\hline 14 & & & 1 & $1(0.9)$ & & 2 & 3 & $5(3.9)$ & 6 \\
\hline 15 & & & 1 & $1(0.9)$ & & & 3 & $3(2.3)$ & 4 \\
\hline Total & 2 & 13 & 96 & 111 & 5 & 15 & 108 & 128 & 239 \\
\hline
\end{tabular}




\begin{tabular}{|c|c|c|c|c|c|c|c|}
\hline & \multicolumn{3}{|c|}{ Female } & \multicolumn{3}{|c|}{ Male } & All \\
\hline & Infective & Other & Total & Infective & Other & Total & Total(\%) \\
\hline Infant(0-3years) & 8 & 25 & 33 & 11 & 36 & 47 & $80(33.5)$ \\
\hline $\begin{array}{l}\text { Pre-School(4- } \\
5 \text { years) }\end{array}$ & 28 & 6 & 34 & 23 & 7 & 30 & $64(26.8)$ \\
\hline $\begin{array}{l}\text { Primary(6- } \\
12 \text { years) }\end{array}$ & 25 & 16 & 41 & 19 & 24 & 43 & $84(35.1)$ \\
\hline $\begin{array}{l}\text { Secondary(12- } \\
\text { 16years) }\end{array}$ & 1 & 2 & 3 & 2 & 6 & 8 & $11(4.6)$ \\
\hline Total (All) & 62 & 49 & 111 & 55 & 73 & 128 & $239(100.0)$ \\
\hline
\end{tabular}

Table 3. The age distribution (clustered) by reason for attendance.

\begin{tabular}{|l|c|c|c|c|}
\hline Condition & Infection(\%) & Injury(\%) & Other(\%) & Total(\%) \\
\hline Indigenous & $16(57.1)$ & $12(42.9)$ & $0(0.0)$ & $28(100)$ \\
\hline Non -Indigenous & $101(47.9)$ & $105(49.8)$ & $5(2.4)$ & $211(100)$ \\
\hline Total & $117(49)$ & $117(49)$ & $5(2)$ & $239(100)$ \\
\hline
\end{tabular}

Table 4. The distribution of reason for attendance for Indigenous and non-Indigenous patients

\begin{tabular}{|l|c|c|c|}
\hline Condition & IN Patient(\%) & OUT Patient(\%) & Total(\%) \\
\hline Infective & $103(65.6)$ & $14(17.1)$ & $117(49)$ \\
\hline Trauma & $54(34.4)$ & $63(76.8)$ & $117(49)$ \\
\hline Other & $0(0.0)$ & $5(6.1)$ & $5(2)$ \\
\hline Total & $157(100)$ & $82(100)$ & $239(100)$ \\
\hline
\end{tabular}

Table 5. The mode of treatment for patients with different presenting complaints.

Conflicts of Interest: NIL

Funding of research: NIL 


\section{Reference}

1. Saintrain MV, Correa CR, Saintrain SV, Nuto Sde A, Vieira-Meyer AP. Brazilian adolescents' oral health trends since 1986: an epidemiological observational study. BMC 2015;12:554. Doi: 10.1186/s13104-0151538-5

2. Alsharif AT, Kruger E, Tennant M. Future projections of child oral-related hospital admission rates in Western Australia. Australian journal of Primary Health 2016. Doi: 10.1071/PY15132

3. Tennant M, Namjoshi D, Silva D, Codde J. Oral health and hospitalization in Western Australian children. Australian Dental Journal 2000;45:204-207. Doi:10.1111/j.1834-7819.2000.tb00558.x

4. Hallett KB, O'Rourke PK. Caries experience in preschool children referred for specialist dental care in hospital. Austalian Dental Journal 2006;51:124-129. Doi: 10.1111/j.1834-7819.2006.tb00415.x

5. Kruger E, Dyson K, Tennant M. Hospitalization of Western Australian children for oral health related conditions: a 5-8 year follow-up. Australian Dental Journal 2006; 51:231-236. Doi:10.1111/j.18347819.2006.tb00434.x

6. Alsharif AT, Kruger E, Tennant M. Dental hospitalization trends in Western Australian children under the age of 15 years: a decade of population-based study. International Journal of Paediatric Dentistry 2015a;25:35-42. Dio:101111/ipd.12095

7. Alsharif AT, Kruger E, Tennant M. A population-based cost description study of oral treatment of hospitalized Western Australian children aged younger than 15 years. Journal of Public Health Dentistry 2015b;75:202209. Dio:10.111/jphd.12088

8. Australian Bureau of Statistics. Estimates of Aboriginal and Torres Strait Islander Australians. Census: ABS, 2011. 'http://www.abs.gov.au'. Accessed August 2013.

9. Walker D, Tennant M, Short SD. An exploration of the priority remote health personnel give to the development of the Indigenous Health Worker oral health role and why: unexpected finding. The Australian Journal of Rural Health 2013;21:274-278.

Doi:10.111/ajr.12045

10. Campbell MA, Hunt J, Walker D, Williams R. The oral health care experiences of NSW Aboriginal Community Controlled Health Services. Australian and New Zealand Journal of Public Health 2015;39:21-25.

Doi:10.1111/1753-6405.12294

11. Andreasen JO, Andreasen FM, Andersson L. Textbook and color atlas of traumatic injuries to the teeth. 4th edn. Oxford: Blackwell Munksgaard, 2007. 